\title{
SPECTROPHOTOMETRIC DETERMINATION OF INDAPAMIDE AND CO-DERGOCRINE MESYLATE
}

\author{
Niveen A. Mohamed \\ Department of Pharmaceutical Analytical Chemistry, Faculty of Pharmacy, Assiut University, \\ Assiut 71526, Egypt
}

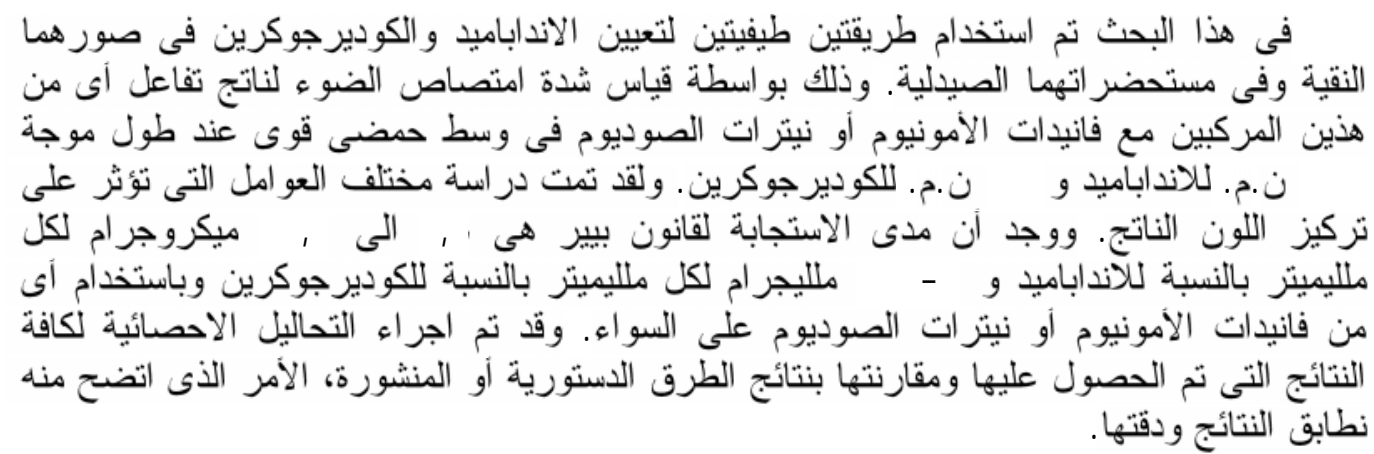

Two simple and sensitive spectrophotometric methods for the determination of indapamide and co-dergocrine in pure form and in pharmaceutical preparations were developed. The methods were based on the interaction of the cited drugs with either ammonium vanadate or sodium nitrite in strongly acidic media. The resulting coloured products were measured at 530 and $550 \mathrm{~nm}$ for indapamide and co-dergocrine respectively. The effect of different variables on the involved reactions and the colour development were studied and optimised. Beer's law was obeyed in the range of 1.8-12 $\mu \mathrm{gl}^{-1}$ for indapamide using ammonium vanadate and sodium nitrite and 12-40 $\mu \mathrm{g} \mathrm{ml}^{-1}$ for co-dergocrine with both ammonium vanadate and sodium nitrite. The reproducibility and recovery of the methods are excellent. The methods were applied successfully to the determination of some commercially available dosage forms purchased from the local market. The results were comparable to those obtained by official or reported methods.

\section{INTRODUCTION}

Indapamide (I) is a sulphonamide derivative that possesses diuretic and potent antihypertensive effects. ${ }^{1}$ Indapamide has been determined spectrophotometrically $y^{2-4}$ electro ehemically, ${ }^{5}$ chromatographically,6-10 and volumetrically. ${ }^{11}$

Co-dergocrine (II) is a mixture of three hydrogenated alkaloids, dihydroergocristine, dihydroergocornine and dihydroergocryptine ( $\alpha$ and $\beta$ ) present approximately in equal ratios. ${ }^{12}$ It is used as $\beta$-blocker antihypertensive drug. Co-dergocrine has been determined by spectrophotometic, ${ }^{13}$ chromatographic ${ }^{14-15}$ and radioimmunoassay ${ }^{16}$ methods.
Few reports including spectrophotometric methods for the assay of indapamide and codergocrine are present in the literature. Most of these methods are tedious and time consuming.

The interaction between some easily oxidized amides and some selected oxidizing agents were investigated previously and developed as a cyclic voltammetric technique for the determination of indapamide. ${ }^{5}$ The applicability of this reaction for developing more simpler, sensitive and time saving spectrophotometric procedures has been investigated in our laboratory. As a result of this investigation two simple, rapid, sensitive and reproducible spectrophotometric methods for determination of indapamide and codergocrine have been developed. 
Both methods were applied successfully for determination of the studied drugs in the commercial dosage forms.<smiles>CC1Cc2ccccc2N1NC(=O)c1ccc(Cl)c(S(N)(=O)=O)c1</smiles>

(I) Indapamide

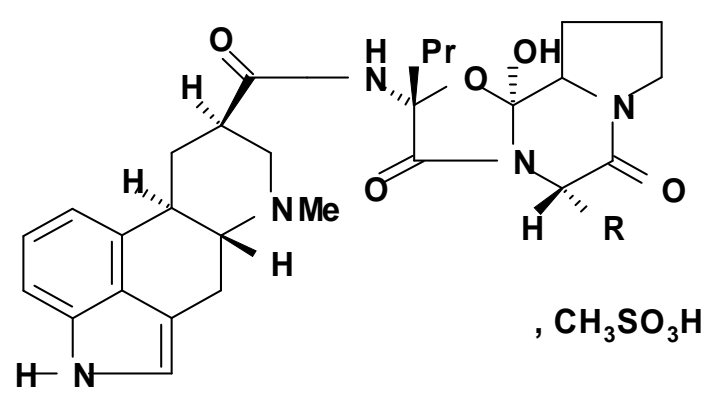

(II) Co-dergocrine Mesilate

Dihydroergocristine: $\quad \mathrm{R}=-\mathrm{CH}_{2} \mathrm{Ph}$

Dihydroergocryptine, $\alpha$ : $\mathrm{R}=-\mathrm{CH}_{2}-\mathrm{CH}-(\mathrm{Me})_{2}$

Dihydroergocryptine, $\beta$ : $\mathrm{R}=-\mathrm{CH}-\mathrm{Me}-\mathrm{CH}_{2}-\mathrm{CH}_{3}$

Dihydroergocornine,: $\quad \mathrm{R}=-\mathrm{CH}-(\mathrm{Me})_{2}$

\section{EXPERIMENTAL}

\section{Appartus}

- Shimadzu UV 1601, UV-VIS spectrophotometer (Kyoto, Japan).

- Shimadzu -IR-470 infrared spectrometer (Kyoto, Japan). IR spectra were recorded as $\mathrm{KBr}$ discs.

\section{Chemicals and reagents}

All chemicals and solvents used were of analytical grade.

\section{Reagents}

Ammonium vanadate solution $(0.5 \% \mathrm{w} / \mathrm{v})$ was prepared by dissolving $0.5 \mathrm{~g}$ of ammonium vanadate (VEB Laborchemie, Apolda, Germany) in the least amount of distilled water and diluted to $100 \mathrm{ml}$ with sulphuric acid ${ }^{17}$ then filtered if necessary.

Sodium nitrite solution $(1 \% \mathrm{w} / \mathrm{v})$ was prepared by dissolving $1.0 \mathrm{~g}$ of sodium nitrite (Panreac, Barcelona, Espana) in $100 \mathrm{ml}$ distilled water.

\section{Pharmaceutical Grade Compounds}

Indapamide (Amriya Pharm, Alexandria, Egypt), co-dergocrine from (October Pharm, Cairo, Egypt). were obtained and used as working standards without further treatment.

Purity tests were carried out by using reported and official methods ${ }^{12,18}$ and were found in the range of the reported value.

\section{Dosage forms}

Natrilix ${ }^{\circledR}$ tablets Batch No. 1A134 (Servier, Cairo, Egypt) labelled to contain 2.5 mg indapamide, durix ${ }^{\circledR}$ tablets Batch No. 415107 (Amriya Pharm, Alexandria, Egypt) labelled to contain $2.5 \mathrm{mg}$ indapamide, hypotense tablets Batch No. S10129 (ADCO, Cairo, Egypt) labelled to contain $2.5 \mathrm{mg}$ indapamide and hydergine tablet Batch No. 125 (Novartis Pharm,Cairo, Egypt) labelled to contain $1.5 \mathrm{mg}$ co-dergocrine mesylate.

\section{Synthetic mixtures}

Indipamide $(2.5 \mathrm{mg})$ or $(1.5 \mathrm{mg})$ codergocrine was mixed well with starch $(25 \mathrm{mg})$, glucose $(25 \mathrm{mg})$, sucrose $(25 \mathrm{mg})$, magnesium stearate $(2.5 \mathrm{mg})$, lactose $(25 \mathrm{mg})$, and gum acacia $(2.5 \mathrm{mg})$ in a morter and used for evaluation of interferences due to common additives and excipients. An amount of the synthetic mixture equivalent to $10 \mathrm{mg}$ of each drug was transferred to a $50-\mathrm{ml}$ volumetric flask, and continued as described under analysis of tablets.

\section{Working standard solutions}

An accurately weighed amount of indapamide or co-dergocrine $(10 \mathrm{mg})$ was transferred into $25-\mathrm{ml}$ volumetric flask, $5 \mathrm{ml}$ methanol portions were added and shaked well then completed to volume with methanol. Suitable dilutions of the solution were made with the methanol to obtain concentrations ranging from $15-120 \mu \mathrm{g} \mathrm{ml}^{-1}$ for indapamide and $60-400 \quad \mu \mathrm{g} \mathrm{ml}^{-1}$ for co-dergocrine respectively. 


\section{Analysis of tablets}

Twenty tablets were weighed and finely powdered after removal of the coloured coat by a piece of cotton wetted with distilled water and the tablets were dried with tissue paper. An accurately weighed amount of the powdered tablets equivalent to $10 \mathrm{mg}$ of either indapamide or co-dergocrine was transferred to $50-\mathrm{ml}$ volumetric flask dissolved in about 20 $\mathrm{ml}$ with methanol. The mixture was sonicated well for about 10 minutes and then diluted to the mark with the same solvent and filtered. The first portion of the filtrate was rejected. The clear solution obtained was used for preparation of the working sample solutions.

\section{Isolation of the coloured product}

A weight equivalent to $10^{-4} \mathrm{M}$ of indapamide was dissolved in $25 \mathrm{ml}$ methanol, then mixed with $5 \mathrm{ml}$ of $10^{-4} \mathrm{M}$ sodium nitrite previously dissolved in double distilled water. The mixture was stirred for 15 minutes, then stored in a vacuum dessicator over anhydrous calcium chloride until a crystalline solid is formed.

\section{General procedure \\ Procedure (A)}

Into 10-ml volumetric flask, 5-ml perchloric acid followed by $0.1 \mathrm{ml}$ sodium nitrite solution was added to $1.0 \mathrm{ml}$ of either standard or sample drug solution, mixed well, allowed to stand for $10 \mathrm{~min}$ at ambient temperature $\left(25 \pm 2^{\circ}\right)$ and then diluted to volume with $35 \%$ perchloric acid. The absorbance was measured at 530 and $550 \mathrm{~nm}$ for indapamide and co-dergocrine respectively, against a blank solution treated similarly.

\section{Procedure (B)}

Into $10-\mathrm{ml}$ volumetric flask, $5 \mathrm{ml}$ perchloric acid followed by $0.1 \mathrm{ml}$ ammonium vanadate for indapamide and $0.2 \mathrm{ml}$ for codergocrine was added to $1.0 \mathrm{ml}$ of either standard or sample drug solution, mixed well, allowed to stand for $10 \mathrm{~min}$ at ambient temperature and then diluted to volume with $35 \%$ perchloric acid. The absorbance was measured at 530 and $550 \mathrm{~nm}$ for indapamide and co-dergocrine, respectively, against a blank solution treated similarly.

\section{RESULTS AND DISCUSSION}

The absorption spectra for the coloured products of the studied drugs from reaction with either ammonium vanadate or sodium nitrite in acid medium exhibit maxima at 530 and $550 \mathrm{~nm}$ for indapamide and co-dergocrine, respectively (Figures 1 and 2).

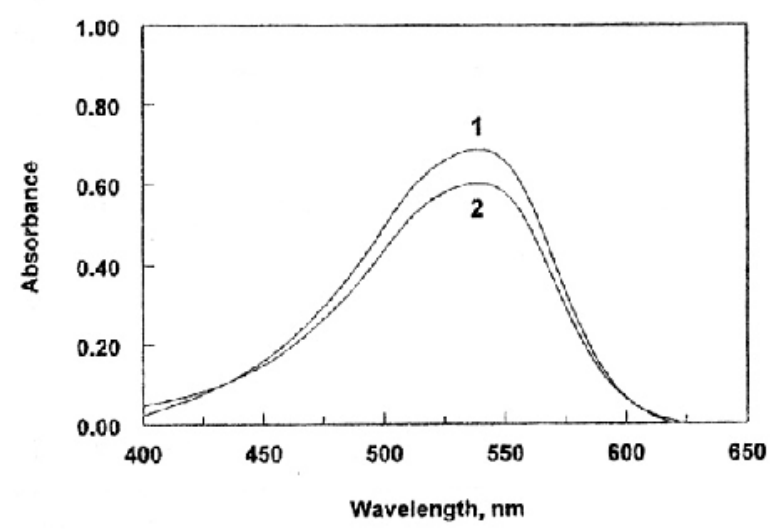

Fig. 1: Absorption spectra of indapamide (8 $\mu \mathrm{g}$ $\mathrm{ml}^{-1}$ ) with ammonium vanadate (1) and sodium nitrite (2).

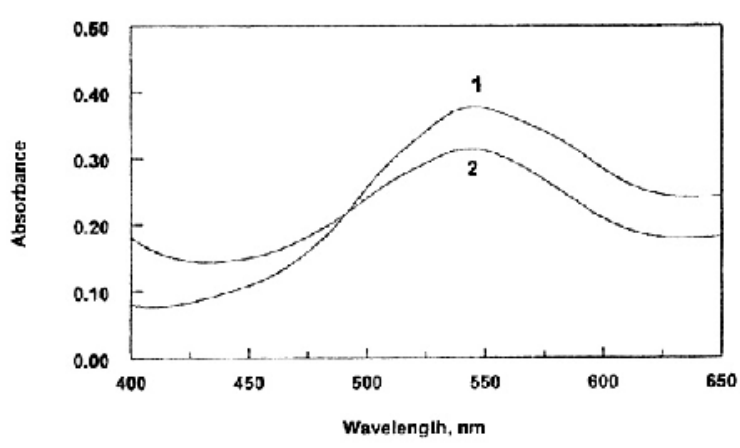

Fig. 2: Absorption spectra of co-dergocrine (15 $\mu \mathrm{g} \mathrm{ml}^{-1}$ ) with ammonium vanadate (1) and sodium nitrite (2).

\section{Optimization of reaction variables}

Investigations were carried out in order to establish the most favourable reaction conditions that affect the assay procedures. It was found that, both reactions occurred only in a strong acidic medium. Several acids in different concentrations were tested. Results showed that both oxalic and citric acid gave no colours, while acetic, nitric and hydrochloric acids gave very weak coloured products. Sulphuric and perchloric acids give more intense violet colours that can be measured spectrophotmetrically. Perchloric acid was 
preferred because it gives the most intense and stable coloured products. In addition, the reaction products with perchloric acid exhibited a single and distinct maximum in all studied drug concentrations Table 1.

Different concentrations of perchloric acid were tested in order to select the most suitable one for determinations. It was found that, maximum colour intensity was obtained with $70 \%$ perchloric acid. Therefore, different volumes of this acid were tested in order to select the most suitable quantity for determinations. It was found that $4-7 \mathrm{ml}$ of perchloric acid gave the most intense and stable coloured products in all cases. Thus $5 \mathrm{ml}$ of $70 \%$. perchloric acid was selected for the subsequent work.

Dilution of the coloured products by different solvents and acid solutions showed that, there was no or slight effect on the position of absorption maxima but absorption intensities were influenced. Table 2 indicates that $35 \%$ perchloric acid $(1: 1)$ is the most suitable diluting solvent because it gives the highest and most stable absorption intensity.

Table 1: Effect of the type of the acid on the absorption spectra of indapamide and co-dergocrine.

\begin{tabular}{|l|c|c|c|c|c|c|c|c|}
\hline \multirow{3}{*}{ Acid } & \multicolumn{3}{|c|}{ Co-dergocrine $\left(15 \mu \mathrm{g} \mathrm{ml}^{-1}\right)$} & \multicolumn{3}{c|}{ Indapamide $\left(8 \mu \mathrm{g} \mathrm{ml}^{-1}\right)$} \\
\cline { 2 - 10 } & Amm. vanadate & \multicolumn{2}{|c|}{ Sod. nitrite } & \multicolumn{2}{c|}{ Amm. vanadate } & \multicolumn{2}{c|}{ Sod. nitrite } \\
\cline { 2 - 9 } & Absorb. & $\lambda_{\max }$ & Absorb. & $\lambda_{\max }$ & Absorb. & $\lambda_{\max }$ & Absorb. & $\lambda_{\max }$ \\
\hline Perchloric & 0.386 & 550 & 0.345 & 550 & 0.660 & 530 & 0.612 & 530 \\
\hline Sulphuric & 0.135 & 550 & 0.247 & 550 & 0.420 & 530 & 0.385 & 530 \\
\hline Hydrochloric & 0.145 & 430 & 0.045 & 405 & 0.125 & 530 & 0.102 & 530 \\
\hline Acetic & 0.078 & 430 & 0.055 & 405 & - & - & - & - \\
\hline Nitric & - & - & - & & 0.075 & 530 & 0.056 & 530 \\
\hline
\end{tabular}

Table 2: Effect of solvents and perchloric acid solutions on the colour intensity of the reaction products of indapamide and co- dergocrine with ammonium vanadate and sodium nitrite.

\begin{tabular}{||l|c|c|c|c||}
\hline \multirow{2}{*}{ Solvent } & \multicolumn{2}{|c|}{ Co-dergocrine $\left(15 \mu \mathrm{g} \mathrm{ml}^{-1}\right)$} & \multicolumn{2}{c||}{ Indapamide $\left(8 \mu \mathrm{g} \mathrm{ml}^{-1}\right)$} \\
\cline { 2 - 5 } & Amm. vanadate & Sod. nitrite & Amm. vanadate & Sod. nitrite \\
\cline { 2 - 5 } & Absorb. & Absorb. & Absorb. & Absorb. \\
\hline Ethanol & 0.300 & 0.258 & 0.619 & 0.575 \\
\hline Methanol & 0.315 & 0.256 & 0.571 & 0.550 \\
\hline Acetonitrile & 0.258 & 0.269 & 0.516 & 0.275 \\
\hline Acetone & 0.360 & 0.300 & 0.619 & 0.215 \\
\hline Isopropranol & 0.300 & 0.254 & 0.555 & 0.446 \\
\hline 35\% Perchloric acid & 0.386 & 0.327 & 0.653 & 0.606 \\
\hline
\end{tabular}


The effect of sodium nitrite or ammonium vanadate concentrations on the cited drugs was studied using concentrations in the range of $0.1-0.6 \% \mathrm{w} / \mathrm{v}$ for ammonium vanadate and 1$5 \% \mathrm{w} / \mathrm{v}$ for sodium nitrite. In case of sodium nitrite the highest absorbance intensity was obtained by using $0.1 \mathrm{ml}$ of $1.0 \% \mathrm{w} / \mathrm{v}$ sodium nitrite solution. For ammonium vanadate the suitable volume is $0.1 \mathrm{ml}$ of $0.5 \% \mathrm{w} / \mathrm{v}$ for indapamide and $0.2 \mathrm{ml}$ for co-dergocrine (Tables 3 and 4). The coloured products were found to be stable for more than $24 \mathrm{~h}$ without any change in absorbance readings at room temperature (Figures 3 and 4).

Table 3: Effect of reagents concentrations on the colour intensity of the reaction products of codergocrine $\left(15 \mu \mathrm{g} \mathrm{ml}^{-1}\right)$ with ammonium vanadate and sodium nitrite.

\begin{tabular}{|c|c|c|c|c|c|}
\hline Amm. vanadate $\%$ & Absorb. & $\lambda_{\max }$ & Sod. nitrite $\%$ & Absorb. & $\lambda_{\max }$ \\
\hline 0.05 & 0.280 & 550 & 0.5 & 0.296 & 550 \\
\hline 0.1 & 0.310 & 550 & 1 & 0.340 & 550 \\
\hline 0.2 & 0.318 & 550 & 2 & 0.332 & 550 \\
\hline 0.3 & 0.330 & 550 & 3 & 0.320 & 550 \\
\hline 0.4 & 0.342 & 550 & 5 & 0.312 & 550 \\
\hline 0.5 & 0.380 & 550 & 6 & 0.302 & 550 \\
\hline 0.6 & 0.360 & 550 & & & \\
\hline
\end{tabular}

Table 4: Effect of reagents concentrations on the colour intensity of the reaction products of indapamide $\left(8 \mu \mathrm{g} \mathrm{ml}^{-1}\right)$ with ammonium vanadate and soduim nitrite.

\begin{tabular}{|c|c|c|c|c|c||}
\hline Amm. vanadate \% & Absorb. & $\lambda_{\max }$ & Sod. nitrite \% & Absorb. & $\lambda_{\max }$ \\
\hline 0.05 & 0.360 & 530 & 0.5 & 0.590 & 530 \\
\hline 0.1 & 0.400 & 530 & 1 & 0.606 & 530 \\
\hline 0.2 & 0.453 & 530 & 2 & 0.574 & 530 \\
\hline 0.3 & 0.530 & 530 & 3 & 0.531 & 530 \\
\hline 0.4 & 0.553 & 530 & 5 & 0.413 & 530 \\
\hline 0.5 & 0.653 & 530 & 6 & 0.380 & 530 \\
\hline 0.6 & 0.467 & 530 & & & \\
\hline
\end{tabular}

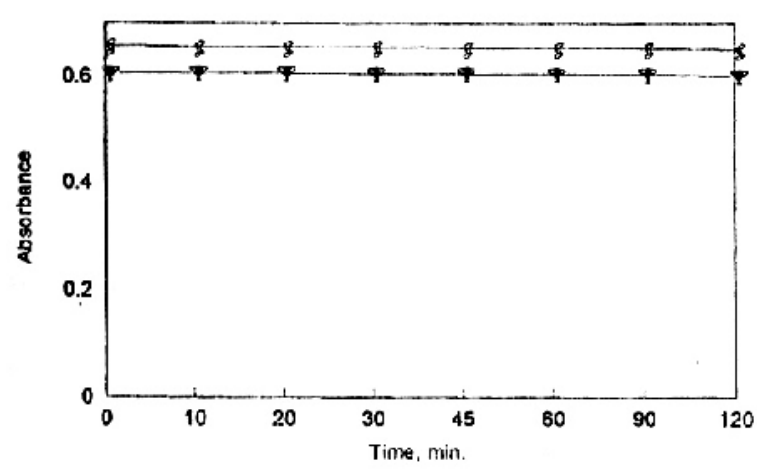

Fig. 3: Stability time of indapamide $(8 \mu \mathrm{g} / \mathrm{ml})$ with (a) ammonium vanadate and (b) sodium nitrite .

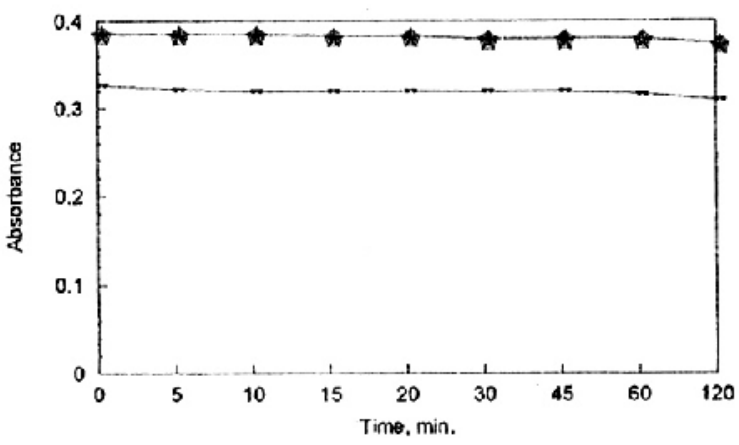

Fig. 4: Stability time of co-dergocrine $(15 \mu \mathrm{g} / \mathrm{ml})$ with (a) ammonium vanadate and (b) sodium nitrite. 


\section{Statistical analysis}

Under the optimum reaction conditions, Beer's law was obeyed. Table 5 shows the linear calibration ranges, regression parameters, and limits of detection and determination for the proposed methods. Relative standard deviation values of the slope and intercepts of the calibration graphs indicated the high reproducibility of the proposed methods.

The proposed methods were applied for the determination of indapamide and co- dergocrine as the drug entity in some pharmaceutical formulations. Recovery experiments were carried out for each drug in its pharmaceutical formulations. The results were compared with those obtained by the official or reported methods. ${ }^{2,14}$ As shown in Table 6 the results are in good agreement with those of the official methods, and the recovery experiments indicated the absence of interferences from the frequently encountered excipients and additives.

Table 5: Quantitative parameters and statistical data for indapamide and co-dergocrine.

\begin{tabular}{||l|c|c|c|c|c|c|}
\hline \hline Drug & $\begin{array}{c}\text { Calibration } \\
\text { range } \\
(\mu \mathrm{g} / \mathrm{mL})\end{array}$ & Intercept $\pm \mathrm{SD}$ & Slope $\pm \mathrm{SD}$ & $\begin{array}{c}\text { Correlation } \\
\text { coefficient } \\
(\mathrm{r})\end{array}$ & $\begin{array}{c}\text { LOD* } \\
(\mu \mathrm{g} / \mathrm{ml})\end{array}$ & $\begin{array}{c}\text { LOQ** } \\
(\mu \mathrm{g} / \mathrm{ml})\end{array}$ \\
\hline \multicolumn{7}{|c|}{ Procedure A } \\
\hline Indapamide & $1.8-12$ & $0.0327 \pm 0.0146$ & $0.0860 \pm 0.0020$ & 0.9990 & 0.51 & 1.70 \\
\hline Co-dergocrine & $12-40$ & $0.0616 \pm 0.0187$ & $0.0157 \pm 0.0007$ & 0.9970 & 3.56 & 11.86 \\
\hline \multicolumn{7}{|c|}{ Procedure B } \\
\hline Indapamide & $1.5-12$ & $0.0263 \pm 0.0130$ & $0.0929 \pm 0.0020$ & 0.9995 & 0.42 & 1.41 \\
\hline Co-dergocrine & $6-40$ & $0.0183 \pm 0.0111$ & $0.0202 \pm 0.0005$ & 0.9990 & 1.66 & 5.52 \\
\hline
\end{tabular}

* Limit of detection.

** Limit of quantitation.

Table 6: Determination of indapamide and co-dergocrine in different formulations by different proposed and reported methods.

\begin{tabular}{||c|c|c|c|}
\hline $\begin{array}{c}\text { Formulation } \\
\text { claimed (mg/tablet) })\end{array}$ & $\begin{array}{c}\text { Amm. vanadate } \\
(\% \text { found } \pm \mathrm{SD})\end{array}$ & $\begin{array}{c}\text { Sodium nitrite } \\
(\% \text { found } \pm \mathrm{SD})\end{array}$ & $\begin{array}{c}\text { Reported } \\
(\% \text { found } \pm \mathrm{SD})\end{array}$ \\
\hline Natrilix ${ }^{(2.5)}$ & $\begin{array}{c}100.9 \pm 0.6^{\mathrm{a}} \\
\mathrm{t}=0.374 \\
\mathrm{~F}=4.54\end{array}$ & $\begin{array}{c}102.3 \pm 0.7 \\
\mathrm{t}=1.574 \\
\mathrm{~F}=3.04\end{array}$ & $101.1 \pm 1.2^{\mathrm{b}}$ \\
\hline Diurex $(2.5)$ & $\begin{array}{c}99.5 \pm 1.1 \\
\mathrm{t}=2.048\end{array}$ & $\begin{array}{c}99.1 \pm 0.7 \\
\mathrm{t}=1.605\end{array}$ & $98.1 \pm 2.0^{\mathrm{b}}$ \\
& $\mathrm{F}=1.057$ & $\mathrm{~F}=2.395$ & \\
\hline Hypotense (2.5) & $\begin{array}{c}101.3 \pm 1.7 \\
\mathrm{t}=2.289\end{array}$ & $\begin{array}{c}100.7 \pm 1.7 \\
\mathrm{t}=1.692\end{array}$ & $98.7 \pm 1.7^{\mathrm{b}}$ \\
Batch No. S10129 & $\mathrm{F}=1.078$ & $\mathrm{~F}=1.104$ & \\
\hline Hydergine (1.5) & $\begin{array}{c}101.8 \pm 1.7 \\
\mathrm{t}=1.408\end{array}$ & $\begin{array}{c}101.2 \pm 1.2 \\
\mathrm{t}=1.764\end{array}$ & $100.1 \pm 1.9^{\mathrm{c}}$ \\
& $\mathrm{F}=1.161$ & $\mathrm{~F}=2.606$ & \\
\hline
\end{tabular}

${ }^{a}$ Average of five determinations.

${ }^{\mathrm{b}}$ Reference 2 and ${ }^{\mathrm{c}}$ reference 14 .

Theoretical values of $\mathrm{F}$ and $\mathrm{t}$ at $95 \%$ confidence limit are 6.39 and 2.776 . 


\section{Reaction pathway}

Scheme 1 shows the possible reaction pathway as predicted from the literature reports and the results of the present work. Radi ${ }^{5}$ reported the stripping voltametry for indapamide and two anodic peaks were observed due to the oxidation of the amide group. The oxidation of the amide group will result in the formation of the structure given in the scheme. There is no positive IR evidence for the formation of $-\mathrm{OH}$ band or disappearance of $-\mathrm{NH}$ band of amide group, due to the presence of $-\mathrm{NH}_{2}$ bands of the sulphamoyl group which overlaps with them, but the absence of the characteristic $\mathrm{C}=\mathrm{O}$ stretching band at $1660 \mathrm{~cm}^{-1}$ is indicated.

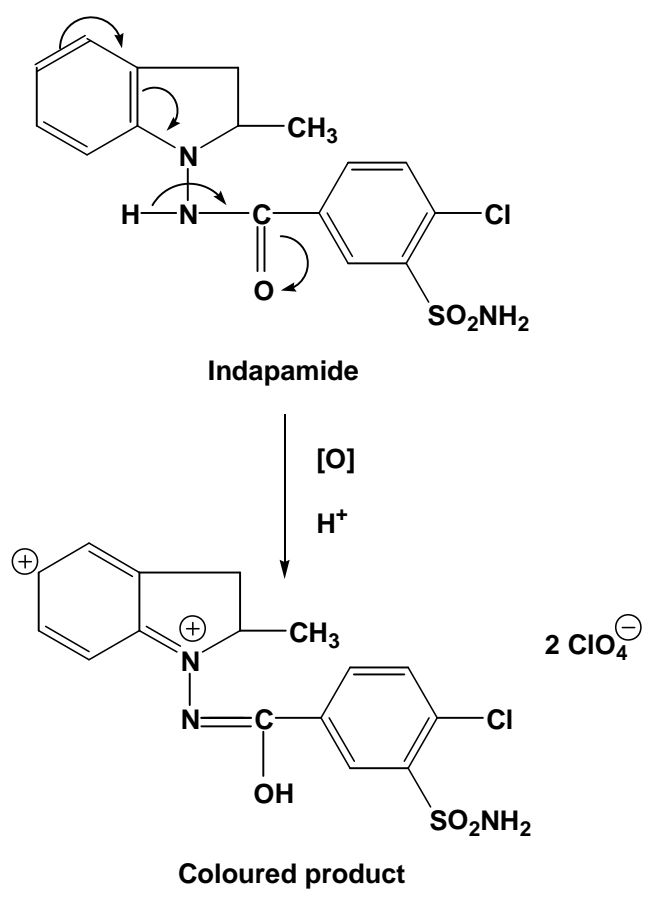

Scheme 1

\section{Interference study}

The influence of frequently encountered excipients such as starch, sucrose, glucose, gum accacia and magnesium stearate on the assays of the both drugs was investigated. No interference was observed even in case of oxidation of some of these excipients.

\section{Conclusion}

The proposed methods are simple, rapid and time saving for analysis of the studied drugs without interference from additives and excipients. The methods also could be successfully used for the routine analysis of the studied drugs in pure forms and in different formulations.

\section{REFERENCES}

1- J. N. Delgado, W. A. Remers, Wilson and Gisvold Text Book of Organic Medicinal and Pharmaceutical Chemistry, $10^{\text {th }}$ Ed., J.B. Lippincott Company, London, 1998, pp. 563-567.

2- Y. K. Agrawal and F. D. Majumdar, Anal. Lett., 28, 169 (1995).

3- M.Y.Ebeid, B. A. Moussa, A. A. Nasr, F. A. Ashour and A. A. Malek, Egypt. J. Pharm. Sci., 35, 578 (1994).

4- N. Erk, J. Pharm Biomed. Anal., 26, 43 (2001).

5- A. Radi, J. Pharm. Biomed. Anal., 24, 413 (2001).

6- M. Y. Ebeid, B. A. Moussa, A. A. Malek and F. A. Ashour, Egypt. J. Pharm. Sci., 3, 171 (1997).

7- M. V. Padval and H. N. Bhargava, J. Pharm. Biomed. Anal., 11, 1033 (1993).

8- R. B. Miller, D. Dadgar and M. Lalande, J. Chromatogr. Biomed. Appl., 614, 293 (1993).

9- United States Pharmacopoeia XXIV, NF XVIV, US Pharmacopeial Convection, Rockville, MD, 2000, p. 867.

10- British Pharmacopeia, H. M. Stationary Office, London, 1998, p. 719.

11- L. Zecca et al., J. Chromat. Biomed. Appl., 272 , 401 (1983).

12- A.C. Moffat, J. V. Jjacksonn, M. S. Moss, B. Widdop and E. S. Reenfield, Clarke's Isolation and Identification of Drugs, $2^{\text {nd }}$ Ed. The Pharmaceutical Press, London, 1986, p. 491.

13- T. Irie, G. Idzu, Y. Hashimoto, M. Ishibashi and $\mathrm{H}$. Miyazaki, Yakugaaku Zashi., 106 (10), 900 (1986). 
14- United States Pharmacopoeia XXIII, NF XVIII, American Pharmaceutical Association, Washington, DC, 1995, p. 602.

15- British Pharmacopoeia, H. M. Stationary Office, London, 1998, p. 380.
16- W. Loh and B. G. Woodcock, Arzneimittel-Forsch., 33, 568 (1983).

17- Reference 12, p.137.

18- T. J. Difeo and J.E. Shuster, in: K. Florey (ed.), Analytical Profiles of Drug Substances, Vol. 23, Academic Press, New York, 1994, p. 229. 